\title{
Seeing satire in the eighteenth century, edited by Elizabeth C. Mansfield and Kelly Malone
}

\section{Francesca Pagani}

\section{(2) OpenEdition}

1 Journals

\section{Edizione digitale}

URL: http://journals.openedition.org/studifrancesi/2149

DOI: 10.4000/studifrancesi.2149

ISSN: 2421-5856

\section{Editore}

Rosenberg \& Sellier

\section{Edizione cartacea}

Data di pubblicazione: 1 aprile 2014

Paginazione: 142-143

ISSN: 0039-2944

\section{Notizia bibliografica digitale}

Francesca Pagani, « Seeing satire in the eighteenth century, edited by Elizabeth C. Mansfield and Kelly Malone », Studi Francesi [Online], 172 (LVIII | I) | 2014, online dal 01 avril 2014, consultato il 18 septembre 2020. URL : http://journals.openedition.org/studifrancesi/2149 ; DOI : https://doi.org/ 10.4000/studifrancesi.2149

Questo documento è stato generato automaticamente il 18 settembre 2020.

\section{(c)}

Studi Francesi è distribuita con Licenza Creative Commons Attribuzione - Non commerciale - Non opere derivate 4.0 Internazionale. 


\title{
Seeing satire in the eighteenth century, edited by Elizabeth C. Mansfield and Kelly Malone
}

\author{
Francesca Pagani
}

\section{NOTIZIA}

Seeing satire in the eighteenth century, edited by Elizabeth C. MANSFIELD and Kelly MALONE, Oxford, Voltaire Foundation, 2013 (SVEC 2013: 2), pp. VIII-320.

1 Il volume della Voltaire Foundation, curato da Elizabeth C. Mansfield e Kelly Malone, porta un contributo essenziale allo studio della satira nel secolo dei Lumi: indissolubilmente legata all'epistemologia dello sguardo, essa rivela le incongruità e le ambizioni del Settecento asserendo e al contempo confutando, in un complesso intreccio di codici culturali, la ricerca delle verità universali. Emmanuel ScHWARTZ evidenzia la pluralità di fonti ispiratrici - talora ben riconoscibili, talora ignote - della satira nelle arti plastiche e figurative, e giunge a ricondurle a una cifra che rovescia l'enunciazione di Goya: il trionfo della ragione genera mostri (Satire unmasked by reading, pp. 15-39). Eric ROSENBERG interpreta il dipinto Boy with a squirrel di John Singleton Copley quale denuncia di un'impossibilità: quella di rappresentare la nuova società americana di metà Settecento con i codici del "vecchio mondo" (The impossibility of painting, pp. 41-62). Julie-Anne PLAX si incentra sull'humor che trapela nell'opera di Watteau leggendolo quale segno della sociabilité, in armonia quindi con convenzioni estetiche e sociali largamente condivise (Watteau's witticisms, pp. 63-80). Emily RICHARDSON analizza il linguaggio allusivo e dissimulatore del Livre de caricatures di SaintAubin, il ricco manoscritto prodotto dal 1735 al 1770 («Tu n'as pas tout vü!», pp. 81-105), che esplora pure Melissa LEE HYDE, soffermandosi sulla simbologia attribuita alla pratica del cucito nella suddivisione dei ruoli tra l'uomo e la donna. La satira di Saint-Aubin si rivolge al contempo alla marchesa di Pompadour, abile cucitrice ma pure influente 
donna di potere, e, in modo scherzoso, a se stesso (Needling: embroidery and satire in the hands of Charles-Germain de Saint-Aubin, pp. 107-130). Kimberly CHRISMAN-CAMPBELL si focalizza sul linguaggio della moda: il manicotto, accessorio maschile, tra esagerazioni e una progressiva perdita d'attualità sul finire del secolo, testimonia da un lato della controversa definizione di mascolinità e dall'altra del sentimento antifrancese imperante nell'Inghilterra del Settecento («He is not dressed without a muff», pp. 131-147). Trevor BURNARD si occupa della satira realizzata dai disegnatori inglesi nel caratterizzare i coloni di pelle bianca delle Indie Occidentali Britanniche quale tipo sociale da disprezzare: lussuriosi, debosciati, attratti dalle donne di pelle nera, il cui corpo è rappresentato come esteticamente sgradevole, al punto da assurgere a emblema della bestialità ( A compound mongrel mixture», pp. 149-165). Reva WOLF, in Seeing satire in the peepshow (pp. 167-196), a partire dal celebre Tuti li mundi di Francisco Goya, esplora il potere metaforico di quello strumento ottico che in Italia fu chiamato il "mondo nuovo", studiandone la diffusione e il portato in Italia e in altri paesi europei. Dal contributo emerge la carica simbolica di un oggetto in grado di rappresentare da un lato la debolezza dell'uomo, pronto a deludere o essere deluso in un'attesa non realizzata, dall'altro la necessità sempre umana di investire le proprie aspettative nelle manifestazioni del "mondo al contrario", El mundo al revès di Goya, quali il carnevale e la magia. Steven MINUK riconduce al pensiero filosofico di Berkeley, Malebranche, Descartes - che Swift ebbe modo di leggere e meditare - i fondamenti della satira della vista e dello sguardo come principale strumento di conoscenza espressa nell'opera dell'autore inglese (Swift's satire of vision, pp. 197-208). Michael yonAN studia alcune sculture di Messerschmidt, i busti denominati Character heads, alla luce dell'influenza di Hogarth e del matematico Lichtenberg (Messerschmidt, the Hogarth of sculpture, pp. 209-226). Katherine MANNHEIMER offre un'illuminante analisi dei testi di Pope e Swift cogliendo una corrispondenza tra l'organizzazione visiva della pagina stampata e il corpo femminile, descritto, inventato e anatomizzato quale oggetto dello sguardo (Anatomizing print's perils, pp. 227-245). Marcus C. LEvITT recupera le fonti popolari del romanzo di Chulkov, spesso ricordato solo rispetto alla letteratura colta che l'ha preceduto («Women's wiles» in Mikhail Chulkov's “The Comely cook”, pp. 247-265). Più di 80 illustrazioni, una ricca bibliografia e un indice esaustivo completano questa pregevole pubblicazione. 